\title{
Hemostatic powder application for control of acute upper gastrointestinal bleeding in patients with gastric malignancy $\square$
}

\section{(ㄷ)(i) $\Theta$}

\author{
Authors \\ Institution \\ Division of Gastroenterology, Department of Internal \\ Medicine, Yonsei University College of Medicine, Seoul, \\ Korea
}

Yeong Jin Kim, Jun Chul Park, Eun Hye Kim, Sung Kwan Shin, Sang Kil Lee, Young Chan Lee nancy. submitted 27.8.2017

accepted after revision 3.1 .2018

\begin{abstract}
Bibliography
DOI https://doi.org/10.1055/a-0593-5884 |

Endoscopy International Open 2018; 06: E700-E705

(c) Georg Thieme Verlag KG Stuttgart · New York

ISSN 2364-3722
\end{abstract}

Corresponding author

Jun Chul Park, MD, Associate professor, Division of

Gastroenterology, Department of Internal Medicine,

Yonsei University College of Medicine, 50, Yonsei-ro,

Seodaemun-gu, Seoul, , Korea

Fax: +82-2-2227-7877

junchul75@yuhs.ac

\section{ABSTRACT}

Background and study aims Despite use of various endoscopic therapies in patients with tumor-related bleeding, various rates of successful immediate hemostasis and short-term rebleeding have been reported. We aimed to evaluate preliminary results of use of the EndoClot polysaccharide hemostatic system (PHS) in patients with acute upper gastrointestinal bleeding (UGIB) from a gastric malig-

Patients and methods We retrospectively analyzed data from a prospectively collected database of 12 patients with acute UGIB from a gastric malignancy who had been treated with EndoClot PHS. The EndoClot air compressor was used to propel $2 \mathrm{~g}$ of absorbable modified polymer particles onto the bleeding site. We checked successful immediate hemostasis, rebleeding events and mortality within 30 days.

Results Twelve patients were enrolled in the study. The median patient age was 72.5 years (range, $57-89$ ). The initial median hemoglobin level was $6.75 \mathrm{~g} / \mathrm{dL}$ (range, 5.4 8.9). The median systolic blood pressure was $114 \mathrm{mmHg}$ (range, 86 -153). Eleven patients had advanced gastric cancer and one patient had a gastrointestinal stromal tumor. The lower body of the stomach was the most common tumor location (58.3\%), and the median tumor size was $40 \mathrm{~mm}$ (range, 15-100). Immediate hemostasis was achieved in all patients, and rebleeding developed in 2 of 12 patients (16\%), 3 and 5 days after treatment. There were no significant Endoclot PHS-related adverse events, and there was no all-cause mortality at 30 days after the intervention.

Conclusions Endoclot PHS represents a new alternative, complementary, and promising therapy for patients with an acute UGIB from a gastric malignancy.

\section{Introduction}

Acute upper gastrointestinal bleeding (UGIB) is an urgent condition that requires close observation and prompt treatment to prevent mortality. Various treatment modalities such as surgical resection, endoscopic therapy (ET), embolization, and radiotherapy can be considered for management of UGIB. In patients with tumor bleeding, optimal hemostasis can be achieved by resection; however, patients with advanced-stage malignancies are frequently poor candidates for resection. In addition, there is a greater risk of recurrent UGIB in patients with a malignant tumor.

Accordingly, endoscopy plays a pivotal role in management of UGIB as a bridge between resuscitation and stabilization and other salvage therapy. With ET, sustained hemostasis can be achieved in $87 \%$ of patients with acute UGIB [1]. However, despite use of various ET in patients with tumor-related bleeding, successful immediate hemostasis rates have been reported variously between $31 \%$ to $100 \%$, and the short-term rebleeding rate can be up to $30 \%$ [2]. This may occur because of secondary injury caused by instrument contact and hypervascularity of 

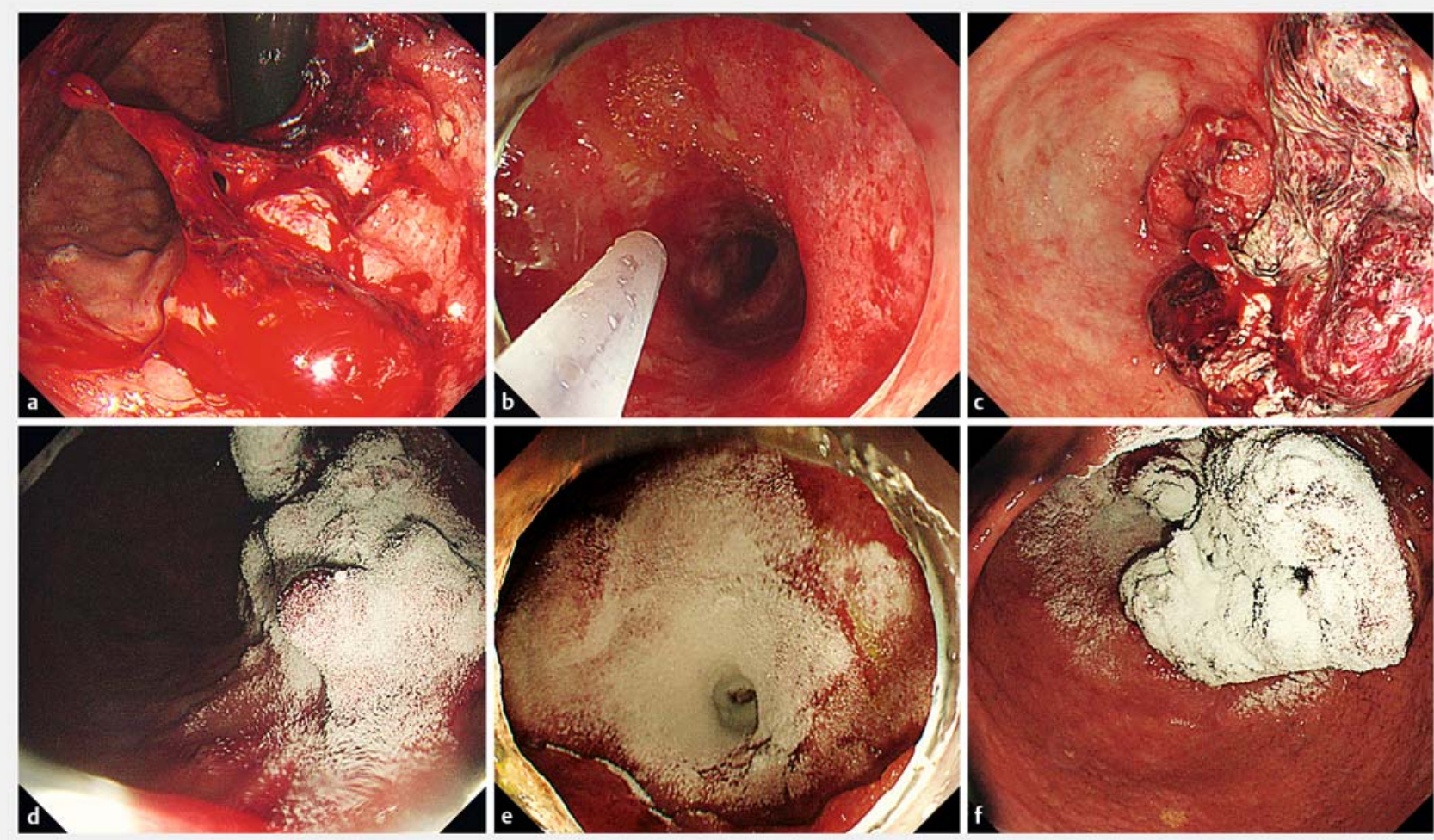

- Fig. 1 Selected cases representing use of EndoClot Polysaccharide Hemostatic System (PHS) for acute gastrointestinal bleeding in patients with a gastric malignancy. a, b, c Active tumor bleeding. d, e, f EndoClot PHS applied at bleeding site. Hemostasis was achieved.

the tumor. Proper delivery of the injection material, mechanical device, or electrical energy to the bleeding site is essential, and this is not always possible with conventional ET, limiting its efficacy.

Recently, application of hemostatic powders to the bleeding site has been used to treat active UGIB [3 - 5]. Hemostatic powders are easy to apply in the stomach regardless of the anatomical location of the bleeding site, and there is no need for direct instrument contact.

The EndoClot Polysaccharide Hemostatic System (PHS) (EndoClot Plus, California, United States) is a novel hemostatic, absorbable, modified polymer particle powder that has been approved for use in non-variceal UGIB. A few tumor bleeding lesions were included in Prei et al.'s study about use of EndoClot PHS in non-variceal UGIB, [5] but exact characteristics and outcomes were not known. In this study we aimed to evaluate preliminary results of use of EndoClot PHS in patients with acute UGIB from a gastric malignancy.

\section{Patients and methods}

\section{Patients}

We retrospectively analyzed data from a prospectively collected endoscopy database of 12 patients with acute UGIB from a gastric malignancy who had been treated with EndoClot PHS between April 2016 and February 2017 at Severance Hospital, Yonsei University College of Medicine in Seoul, Korea.
This preliminary study was designed to evaluate safety and efficacy of EndoClot PHS for treatment of patients with acute UGIB from a gastric malignancy. The inclusion criteria were age $\geq 18$ years, presence of hematemesis, hematochezia, or melena, and presence of active bleeding from a gastric tumor observed by endoscopy within 24 hours of hospital admission. Exclusion criteria were known hypersensitivity to starch, presence of a vascular shunt in the body, pregnancy or lactation, and contraindication to undergoing endoscopy.

The primary outcomes of this study were immediate hemostasis and rebleeding events within 30 days of endoscopic treatment. Secondary outcomes were the frequencies of additional surgery or interventions required to achieve hemostasis. Immediate hemostasis was defined as no detectable bleeding from the treated lesion beyond 5 minutes after application of EndoClot PHS.

Rebleeding was defined as recurrence of hematemesis, hematochezia, or melena and a $>2 \mathrm{~g} / \mathrm{dL}$ drop in the hemoglobin level with recurrent active bleeding observed with endoscopy.

In addition, patient age, gender, American Society of Anesthesiologists score, initial hemoglobin level, hemodynamic stability, amount of transfused packed red blood cells, Forrest classification, tumor type, tumor location, tumor size, previous treatment history, comorbidities, drug usage, Glasgow-Blatchford score (GBS), AIMS65 score, Rockwall score, and adverse event were analyzed. 
- Table 1 Clinical characteristics of acute uppergastrointestinal bleeding in patients with gastric malignancy

\begin{tabular}{|c|c|}
\hline Clinical characteristics & $n=12$ \\
\hline Age, $y r^{1}$ & $72.5(57-89)$ \\
\hline Sex (Male : Female) & $4: 1$ \\
\hline ASA score $^{1}$ & $3(2-4)$ \\
\hline Hemoglobin, g/dL ${ }^{1}$ & $6.75(5.4-8.9)$ \\
\hline $\mathrm{SBP}, \mathrm{mmHg}{ }^{1}$ & $114(86-153)$ \\
\hline - $\mathrm{SBP}<90 \mathrm{mmHg}$ & $1(8.3 \%)$ \\
\hline Pulse rate, $/ \min ^{1}$ & $76.5(57-107)$ \\
\hline Transfusion $\geq 3$ packs & $7(58.3 \%)$ \\
\hline Forrest Ib & $12(100.0 \%)$ \\
\hline \multicolumn{2}{|l|}{ Location } \\
\hline - Upper & $2(16.7 \%)$ \\
\hline - Middle & 0 \\
\hline - Lower & $7(58.3 \%)$ \\
\hline - Diffuse & $3(25.0 \%)$ \\
\hline Tumor size, $\mathrm{mm}^{1}$ & $40(15-100)$ \\
\hline \multicolumn{2}{|l|}{ Previous therapy } \\
\hline - Chemotherapy & $6(50.0 \%)$ \\
\hline Antiplatelet agent use & $3(25.0 \%)$ \\
\hline Glasgow-Blatchford score ${ }^{1}$ & $11(7-15)$ \\
\hline AIMS65 score $^{1}$ & $2(1-3)$ \\
\hline Rockall score $^{1}$ & $8(5-10)$ \\
\hline \multicolumn{2}{|c|}{$\begin{array}{l}\text { ASA, American Society of Anesthesiologists; SBP, systolic blood pressure } \\
{ }^{1} \text { Data represented as median value (range) }\end{array}$} \\
\hline
\end{tabular}

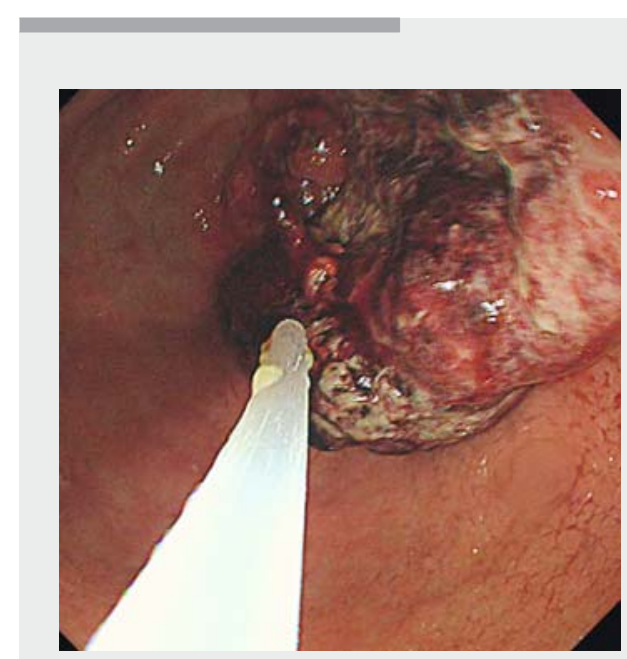

Video 1 Selected case representing use of EndoClot Polysaccharide Hemostatic System (PHS) for acute gastrointestinal bleeding in patients with a gastric malignancy.

\section{Instruments and endoscopic procedure}

EndoClot PHS was used as the hemostatic agent. For hemostasis, we used $2 \mathrm{~g}$ of the absorbable modified polymer (AMP) particles.

Medical resuscitation was initiated in all patients, and therapeutic esophagogastroduodenoscopy was performed by one experienced endoscopist (JCP).

When the bleeding site was reached, the EndoClot air compressor was used to propel the AMP particles out of the delivery catheter onto the bleeding site ( $\triangleright$ Fig. 1 and $\triangleright$ Video 1 ).

Additional established ET techniques including epinephrine injection, argon plasma coagulation, hemoclipping, and electrocoagulation were combined with EndoClot PHS if EndoClot PHS monotherapy was insufficient for achieving complete hemostasis.

After endoscopy, all patients received standard post-endoscopic medical therapy with a continuous infusion of an intravenous proton pump inhibitor (PPI) over 72 hours and continuation of an oral PPI for at least 1 month after the infusion. Routine second-look endoscopy was not performed.

\section{Results}

\section{Patient characteristics}

Twelve patients were enrolled in the study. Table 1 and - Table 2 show the characteristics of the enrolled patients. Median patient age was 72.5 years (range, $57-89$ ) and eight patients were men. The initial median hemoglobin level was $6.75 \mathrm{~g} / \mathrm{dL}$ (range, 5.4-8.9). Median systolic blood pressure (SBP) was $114 \mathrm{mmHg}$ (range, $86-153$ ). One patient had a SBP $<90 \mathrm{mmHg}$. Median pulse rate was 76.5/min (range, $57-107$ ). All patients were categorized as Forrest classification Ib. The lower body of the stomach was the most common tumor location (58.3\%), and the median tumor size was $40 \mathrm{~mm}$ (range, $15-100)$. Half the patients had received chemotherapy before the bleeding event. Eleven patients had advanced gastric cancer (AGC), and one patient had a gastrointestinal stromal tumor. Three patients were using antiplatelet agents at the time of the bleeding event. Median GBS, AIMS65 score, and Rockall score were 11,2 , and 8 , respectively.

\section{Initial hemostasis and rebleeding}

- Table 3 shows outcomes of our study. Immediate hemostasis was achieved in all patients and none of them required additional intervention or surgery. EndoClot PHS monotherapy was sufficient to achieve hemostasis in 7 of 12 patients. Five patients required combined ET. Rebleeding developed in 2 of 12 patients (16\%), 3 and 5 days after treatment. Both patients had thrombocytopenia with platelet counts of $15,000 / \mu \mathrm{L}$ and $64,000 / \mu \mathrm{L}$. One of these patients had AGC with multiple bone metastases and had received 13 cycles of capecitabine and cisplatin chemotherapy; however, the tumor had progressed and the patient had recently developed liver metastases around the time of the acute UGIB. The other patient had AGC with adrenal, periureteral, and peritoneal metastasis. The patient 


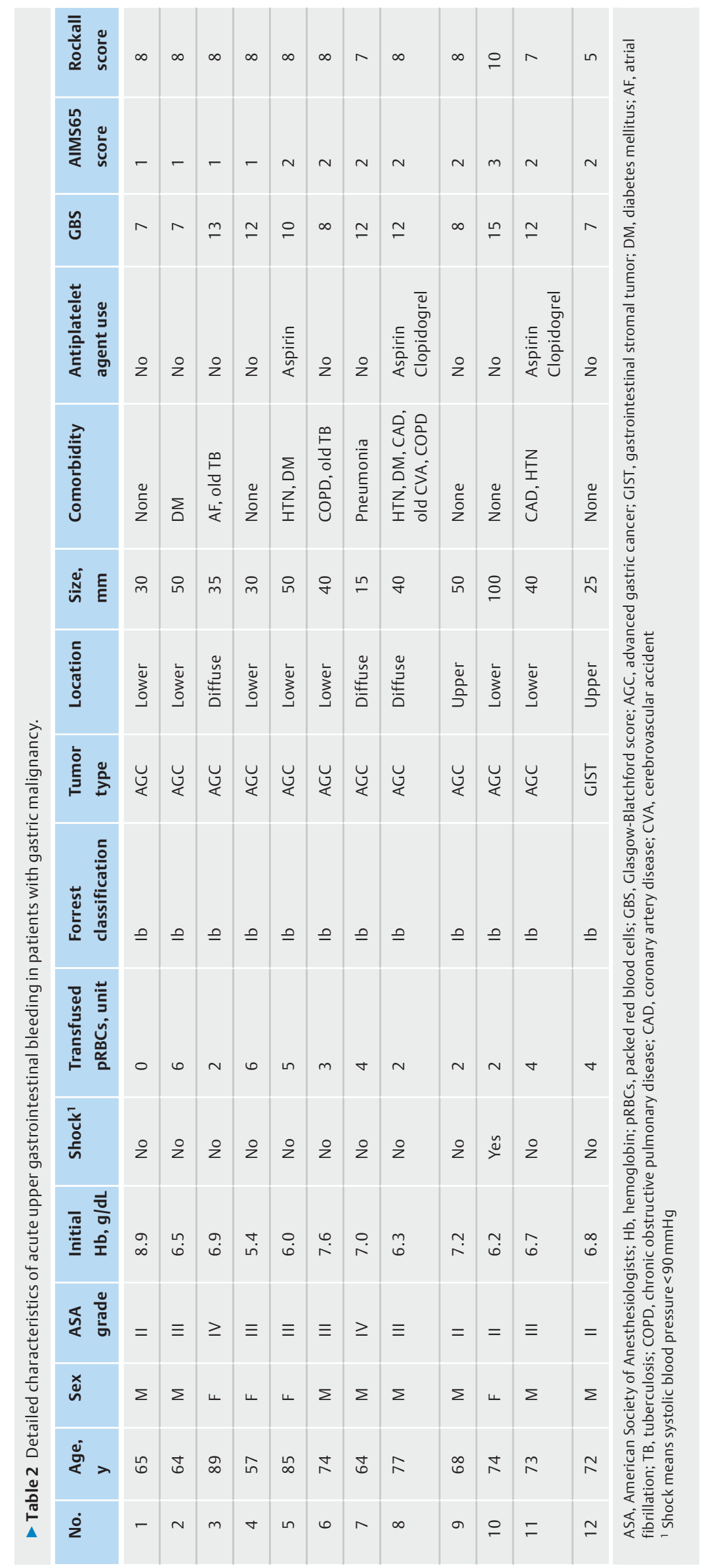


- Table 3 Outcomes of acute upper gastrointestinal bleeding in patients with gastric malignancy treated with Endoclot polysaccharide hemostatic system.

\begin{tabular}{|l|c|}
\hline Outcomes & $\mathbf{n = 1 2}$ \\
\hline Immediate hemostasis & $12(100 \%)$ \\
\hline Rebleeding event in 30 days & $2(16 \%)$ \\
\hline Combined ET & $5(41 \%)$ \\
\hline - Epinephrine only & 3 \\
\hline - APC only & 1 \\
\hline - Epinephrine plus hemoclip plus electrocoagulation & 1 \\
\hline Additional surgery or intervention & 0 \\
\hline Adverse event & 0 \\
\hline Mortality in 30 days & 0 \\
\hline ET, endoscopic therapy; APC, argon plasma coagulation & \\
\hline
\end{tabular}

had received 3 cycles of capecitabine and oxaliplatin chemotherapy.

There were no significant EndoClot PHS-related adverse events, and there was no all-cause mortality at 30 days after the intervention.

\section{Discussion}

Patients with acute UGIB and malignancy have a poor prognosis, and substantial blood loss and rebleeding events require repeated hospitalizations [6]. Median survival in these patients is approximately 6 months [7]. To improve survival, it is essential to achieve complete and sustained hemostasis. ET is generally accepted as first-line treatment for all causes of UGIB and it reduces further bleeding, decreases the need for surgery, and decreases mortality [8].

EndoClot PHS consists of AMPs, which are biocompatible absorbable hemostatic polysaccharides. When applied to a bleeding site, AMPs rapidly absorb water from the blood, causing a high concentration of platelets, red blood cells, and coagulation proteins that accelerates the physiologic clotting cascade. The interaction of AMP particles with blood rapidly produces a gelled matrix that adheres to and seals the bleeding tissue [9].

Huang et al. first applied EndoClot PHS for control and prevention of endoscopic mucosal resection-related bleeding and showed the safety and simplicity of its application [10]. Additional studies have demonstrated that EndoClot PHS is therapeutically applicable for diffuse or extensive bleeding, difficult-to-access bleeding sites, and as a bridge to surgery when prior attempts at hemostasis have failed [11].

Our study is the first to examine the usefulness of EndoClot PHS for hemostasis in patients with an acute UGIB from a gastric malignancy. Although the number of study patients was small, immediate hemostasis was achieved in all patients, regardless of the tumor location, type, size, or previous use of antiplatelet agents. Only 2 cases of rebleeding occurred in our 12 patients (16\%). Our data regarding the efficacy of EndoClot $\mathrm{PHS}$ in patients with a gastric malignancy bleeding are promising in comparison to other modalities reported in previous studies. Table 4 summarizes the results of those previous studies. The rate of immediate hemostasis with conventional ET in patients with acute UGIB from a malignant tumor was between $31 \%$ and $100 \%[6,12-18]$. However, extensive effort and time are needed to achieve immediate hemostasis in patients with large bleeding tumors or oozing multifocal bleeding. Rte of rebleeding in previous studies have been reported to be between $33 \%$ and $86 \%[6,12,15,17]$, which is much higher than that seen in our study (16\%). In addition, none of the patients in our study developed treatment-related adverse

Table 4 Results of endoscopic therapy for acute upper gastrointestinal bleeding in patients with gastric malignancy.

\begin{tabular}{|c|c|c|c|c|c|c|}
\hline Author & $\begin{array}{l}\text { Pub- } \\
\text { lished } \\
\text { year }\end{array}$ & $\begin{array}{l}\text { Number } \\
\text { of total } \\
\text { patients }\end{array}$ & $\begin{array}{l}\text { Number of } \\
\text { stomach } \\
\text { lesions (\%) }\end{array}$ & $\begin{array}{l}\text { Number of } \\
\text { immediate } \\
\text { hemostasis (\%) }\end{array}$ & $\begin{array}{l}\text { Number of } \\
\text { rebleeds in total } \\
\text { patients (\%) }\end{array}$ & $\begin{array}{l}\text { Number of rebleeds in } \\
\text { previously achieved suc- } \\
\text { cessful hemostasis (\%) }\end{array}$ \\
\hline Loftus LV et al. [12] & 1994 & 15 & $11(73)$ & $10(67)$ & $13(86)$ & $8(80)$ \\
\hline Savides T] et al. [13] & 1996 & 7 & NA & $7(100)$ & NA & NA \\
\hline Kurt M et al. [14] & 2010 & 7 & $7(100)$ & $7(100)$ & NA & NA \\
\hline Sheibani S et al. [6] & 2013 & 14 & NA & $12(85)$ & $7(50)$ & NA \\
\hline Kim YI et al. [15] & 2013 & 113 & $113(100)$ & $105(92)$ & NA & $43(40)$ \\
\hline Koh KH et al. [16] & 2013 & 45 & $45(100)$ & $14(31)$ & NA & NA \\
\hline Maluf-Filho F et al. [17] & 2013 & 7 & NA & $6(85)$ & NA & $2(33)$ \\
\hline Martins BC et al. [18] & 2016 & 15 & NA & $11(73)$ & NA & NA \\
\hline Our study & - & 12 & $12(100)$ & $12(100)$ & $2(16)$ & $2(16)$ \\
\hline
\end{tabular}


events such as bowel obstruction or embolism, and the allcause mortality at 30 days was $0 \%$.

Application of EndoClot PHS can disrupt tumor bleeding by accelerating the physiologic clotting cascade and producing a gelled matrix that remains on the bleeding site and protects it from gastric acid. Therefore EndoClot PHS can be applied safely and easily to difficult anatomical positions and can be used to simultaneously cover large multiple bleeding points from a feeding vessel. In contrast to conventional ET, which requires precise localization of the bleeding site and targeted therapy, EndoClot PHS does not require special skill to apply; the current or suspected bleeding lesion is targeted and the AMP particles are propelled onto the lesion. Therefore, the operator does not need to contact the bleeding area, and there is no risk of direct contact inducing secondary bleeding of the tumor. As a result, EndoClot PHS has the advantage of safe and rapid application of hemostatic therapy in comparison to use of conventional ET.

Limitations of our study were the small number of cases and the choice of treatment modality was not determined by the study protocol. In addition, even though most bleeding characteristic of gastric malignancy is oozing type (Forrest Ib), we cannot generalize the efficacy of EndoClot PHS to patients with other Forrest classifications, especially the spurting type Ib because all the patients in our study were categorized as Forrest Ib. Finally, our study did not have a control group for comparison with the EndoClot PHS group, and our data were compared with that of prior studies.

However, despite these limitations, this is the first study providing detailed analysis of use of EndoClot PHS for patients with UGIB from gastric malignancy. Our data demonstrate the efficacy of EndoClot PHS as a new hemostatic method in patients with bleeding from a gastric malignancy. Larger studies with other Forrest classification patients are needed to fully evaluate the efficacy and safety of EndoClot PHS.

\section{Conclusion}

In conclusion, EndoClot PHS represents a new alternative, complementary, and promising therapy for patients with acute UGIB from a gastric malignancy.

\section{Competing interests}

None

\section{References}

[1] Hearnshaw SA, Logan RF, Lowe D et al. Acute upper gastrointestinal bleeding in the UK: patient characteristics, diagnoses and outcomes in the 2007 UK audit. Gut 2011; 60: 1327-1335
[2] Heller S], Tokar JL, Nguyen MT et al. Management of bleeding GI tumors. Gastrointest Endosc 2010; 72: 817-824

[3] Sung JJ, Luo D, Wu JC et al. Early clinical experience of the safety and effectiveness of Hemospray in achieving hemostasis in patients with acute peptic ulcer bleeding. Endoscopy 2011; 43: 291 - 295

[4] Beg S, Al-Bakir I, Bhuva M et al. Early clinical experience of the safety and efficacy of EndoClot in the management of non-variceal upper gastrointestinal bleeding. Endosc Int Open 2015; 3: E605-E609

[5] Prei JC, Barmeyer C, Bürgel N et al. Endoclot polysaccharide hemostatic system in nonvariceal gastrointestinal bleeding: results of a prospective multicenter observational pilot study. J Clin Gastroenterol 2016; 50: e95-e100

[6] Sheibani S, Kim J], Chen B et al. Natural history of acute upper GI bleeding due to tumours: short-term success and long-term recurrence with or without endoscopic therapy. Alimentary Pharmacol Ther 2013; 38: $144-150$

[7] Park H, Ahn JY, Jung HY et al. Can endoscopic bleeding control improve the prognosis of advanced gastric cancer patients? a retrospective case-control study J Clin Gastroenterol 2017; 51: 599-606

[8] Cook DJ, Guyatt GH, Salena B] et al. Endoscopic therapy for acute nonvariceal upper gastrointestinal hemorrhage: a meta-analysis. Gastroenterology 1992; 102: 139-148

[9] EndoClot Plus, Inc. Polymer Solution for hemostasis. Available from: http://endoclot.com/technology.html [Accessed 2017 Jul 1]

[10] Huang R, Pan Y, Hui N et al. Polysaccharide hemostatic system for hemostasis management in colorectal endoscopic mucosal resection. Dig Endosc 2014; 26: $63-68$

[11] Prei JC, Barmeyer C, Burgel N et al. EndoClot Polysaccharide Hemostatic System in Nonvariceal Gastrointestinal Bleeding: Results of a Prospective Multicenter Observational Pilot Study. J Clin Gastroenterol 2016; 50: e95 - e100

[12] Loftus EV, Alexander GL, Ahlquist DA et al. Endoscopic treatment of major bleeding from advanced gastroduodenal malignant lesions. Mayo Clinic proceedings 1994; 69: 736 - 740

[13] Savides TJ, Jensen DM, Cohen J et al. Severe upper gastrointestinal tumor bleeding: endoscopic findings, treatment, and outcome. Endoscopy 1996; 28: 244-248

[14] Kurt M, Akdogan M, Onal IK et al. Endoscopic topical application of Ankaferd Blood Stopper for neoplastic gastrointestinal bleeding: A retrospective analysis. Dig Liver Dis 2010; 42: 196-199

[15] Kim YI, Choi IJ, Cho S] et al. Outcome of endoscopic therapy for cancer bleeding in patients with unresectable gastric cancer. J Gastroenterol Hepatol 2013; 28: 1489-1495

[16] Koh KH, Kim K, Kwon DH et al. The successful endoscopic hemostasis factors in bleeding from advanced gastric cancer. Gastric Cancer 2013; 16: 397-403

[17] Maluf-Filho F, Martins BC, de Lima MS et al. Etiology, endoscopic management and mortality of upper gastrointestinal bleeding in patients with cancer. United European Gastroenterol J 2013; 1: 60-67

[18] Martins BC, Wodak S, Gusmon CC et al. Argon plasma coagulation for the endoscopic treatment of gastrointestinal tumor bleeding: A retrospective comparison with a non-treated historical cohort. United European Gastroenterol J 2016; 4: 49-54 